\title{
A LOW COST ADSORBENT FROM AGRICULTURAL WASTE CORN COB BY ZINC CHLORIDE ACTIVATION
}

\author{
W. T. Tsai, ${ }^{a *}$ C. Y. Chang ${ }^{b} \&$ S. L. Lee ${ }^{b}$ \\ ${ }^{a}$ Department of Environmental Engineering and Health, Chia Nan College of Pharmacy and Science, Tainan 717, Taiwan \\ ${ }^{h}$ Graduate Institute of Environmental Engineering, National Taiwan University, Taipei 106, Taiwan
}

(Received 16 April 1997; revised version received 15 October 1997; accepted 20 October 1997)

\begin{abstract}
A series of activated carbons were prepared from agricultural waste corn cob by the chemical activation with zinc chloride $\left(\mathrm{ZnCl}_{2}\right)$. The effect of process variables such as pyrolysis temperature, soaking time and $\mathrm{ZnCl}_{2}$ /corn cob ratio (impregnation ratio) of the production of adsorbent was examined. The most important parameter in the chemical activation of com cob with $\mathrm{ZnCl}_{2}$ was found to be the impregnation ratio. The percentage of micropore was observed to decrease at higher impregnation ratios. The pyrolysis (or activation) temperature is another important variable, which had a significant effect on the pore surface area evolution. Under the experimental conditions investigated, the temperature of $773 \mathrm{~K}$ was found to be the optimal condition for producing high surface area carbons with $\mathrm{ZnCl}_{2}$ activation. This study showed that the $\mathrm{ZnCl}_{2}$ activation of corn cob was suitable for the preparation of activated carbons which are essentially microporous. (C) 1998 Published by Elsevier Science Ltd. All rights reserved
\end{abstract}

Key words: activated carbon, corn cob, zinc chloride, chemical activation, physical characteristics.

\section{INTRODUCTION}

In the past few years, corn has gained considerable importance as one of the economic sources of cellulose products in Taiwan due to the governmental policy of agricultural cultivation. However, thousands of tons of corn cob remain unused as agricultural wastes in fields and factories (Yang et al., 1991). A large number of studies on the thermochemical conversion of biomass, particularly on the pyrolysis, have been carried out (Maschio et al., 1992). It has been found that the pyrolysis may be a promising route for the biomass utilization in the production of valuable products.

*Author to whom all correspondence should be addressed.
It is well known that activated carbons can be prepared from a large variety of raw materials with a high carbon content and low levels of inorganic compounds. The most frequently used materials or precursors are coal, wood and coconut in the commercial products (Noll et al., 1992). In addition, some agricultural by-products or wastes can be used as raw materials for preparing activated carbons or adsorbents to apply in the removal of some organic and inorganic compounds from liquid and gas phases (Pollard et al., 1992). During the past 10 years there has been considerable research concerning the preparation of low-cost activated carbon from agricultural wastes such as almond shell (Torregrosa and Martin-Martinez, 1991; DomingoGarcia et al., 1991; Rodriguez-Reinoso and MolinaSabio, 1992; Guzel and Tez, 1993; Gergova et al., 1994), peach stones (Rodriguez-Reinoso and Molina-Sabio, 1992), apricot stones (Philip and Girgis, 1996), cherry and olive stones (Lessier et al., 1994), peanut hull (Periasamy and Namasivayam, 1995), nut shells (Nguyen et al., 1995), rice husks (Khalil, 1996), oil palm shells (Hussein et al., 1996), and sugarcane bagasse (Girgis et al., 1994).

Generally, the manufacture of activated carbon involves two main steps: the carbonization of the carbonaceous raw material below $1073 \mathrm{~K}$ in the absence of oxygen, and the activation of the carbonized product (i.e. char). In the chemical activation process these two steps are carried out simultaneously using chemical activating agents as dehydrating agents and oxidants (Bansal et al., 1988). The physical activation, on the other hand, involves carbonization of a carbonaceous precursor followed by the activation of the resulting char at elevated temperature in the presence of activating agents such as carbon dioxide or steam. It has been found that the temperatures used in the chemical activation are lower than those used in the physical activation. Therefore, the development of a porous structure is better for the chemical activation process (Ahmadpour and Do, 1996). It has also 
been observed that the high conversion of the precursor to carbon can be obtained as a result of the inhibition of tar production by chemical agents, hence enhancing the carbon yield (Philip and Girgis, 1996). Among the chemical activating agents, zinc chloride $\left(\mathrm{ZnCl}_{2}\right)$ in particular is the most widely used chemical in the preparation of activated carbon (Bansal et al., 1988).

Studies on the utilization of corn cob as a precursor for manufacturing activated carbons are minimal. In addition, information concerning the chemical characteristics of the resulting activated carbon has not been reported. Therefore, the aim of this study is to describe the feasibility of the preparation of activated carbons from agricultural waste corn cob by chemical activation with $\mathrm{ZnCl}_{2}$. The physical and chemical characteristics of the resulting activated carbon were analyzed and used to establish the appropriate operating conditions including pyrolysis (or activation) temperature, soaking time and $\mathrm{ZnCl}_{2}$ impregnation ratio.

\section{METHODS}

\section{Pretreatment of corn cob}

Dry corn cob, which was crushed and separated from its pitch/chaff and sieved to mesh ranges of $12 \times 16$ (average particle diameter of $1.44 \mathrm{~mm}$ ), was used in this study. The corn cob thus treated was washed with distilled water in order to reduce the residues content, then dried at $378 \mathrm{~K}$ for at least $12 \mathrm{~h}$, before use in the experiments.

\section{Impregnation of corn cob}

Fifty grams of the air-dried corn cob and $10-100 \mathrm{~g}$ of $\mathrm{ZnCl}_{2}$ were well stirred in $200 \mathrm{~cm}^{3}$ of distilled water using a hot plate/magnetic stirrer. The ratio of the precursor (i.e. corn cob) to the $\mathrm{ZnCl}_{2}$ solution was kept constant. Impregnation was carried out at approximately $358 \mathrm{~K}$ in a boiler-reflux condenser for $2 \mathrm{~h}$. Several impregnation ratios, defined as the ratios of the mass of $\mathrm{ZnCl}_{2}$ to that of corn cob, were applied to prepare the impregnated samples. The impregnated sample was then filtered with a vacuum flask and dried at $378 \mathrm{~K}$ for about $24 \mathrm{~h}$.

\section{Experimental apparatus and methods}

A schematic diagram of the experimental apparatus is shown in Fig. 1. For all experiments, the mass ( $\approx 20 \mathrm{~g}, W_{1}$, in each set of experiments) of the impregnated corn cob was placed in a stainless steel (S.S. 316) holder with net in the bottom, then housed at the center of a stainless steel (S.S. 316) tubular reactor of $800 \mathrm{~mm}$ length and $50 \mathrm{~mm}$ diameter. This reactor was placed vertically inside an electric tube furnace controlled by the proportional integral derivative (PID) controller. The temperatures of the reaction zone were measured by the chromel-alumel (K-type) thermocouples (Watlow Gordon Co., Richmond, IL, U.S.A.; model type: grounded junction with sheath materials of 310 stainless steel).

The nitrogen gas from a cylinder was dried and purified by molecular sieve tube. The constant nitrogen flow rate of $300 \mathrm{~cm}^{3} / \mathrm{min}$ at standard temperature and pressure (STP) was metered precisely to the experimental system using a mass flow controller. The experimental conditions of the chemical activation were as follows: impregnation ratio of $20-200 \mathrm{wt} \%$, heating rate of $10 \mathrm{~K} / \mathrm{min}$, pyrolysis temperature of $673-1073 \mathrm{~K}$, and soaking time of $0 \cdot 5-4 \cdot 0 \mathrm{~h}$.

For preliminary comparison, a series of activated carbons were also prepared by physical activation

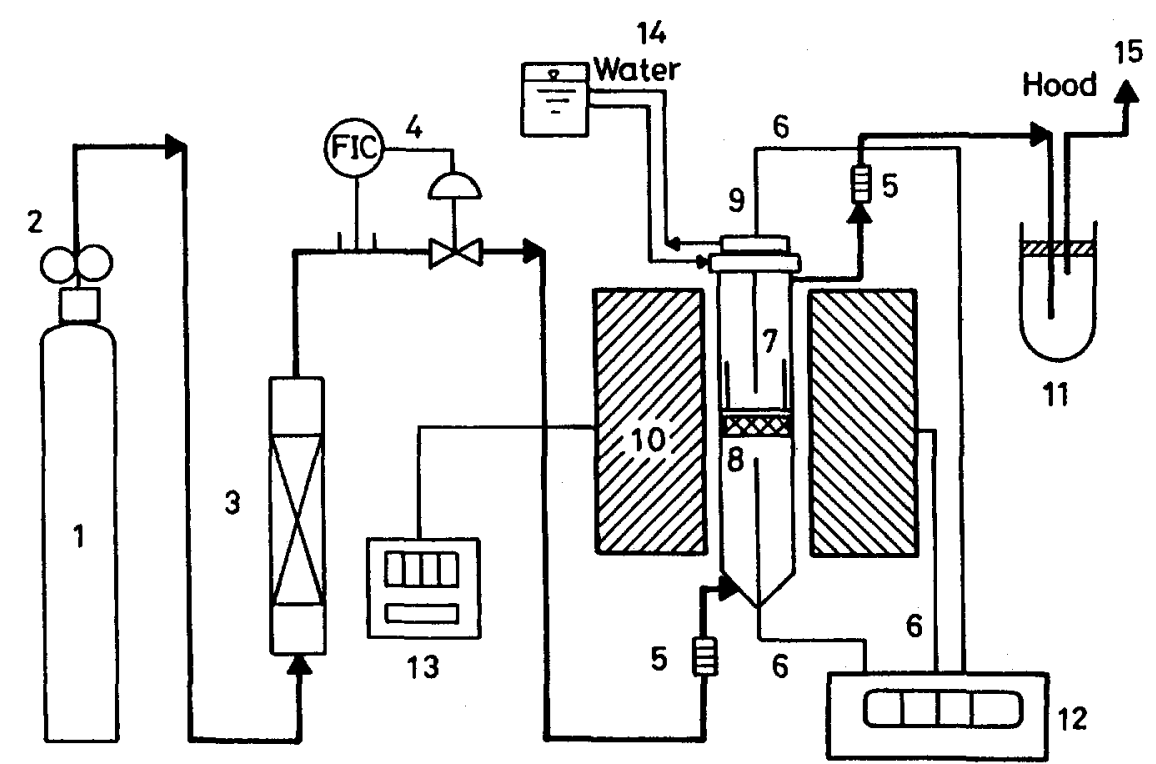

Fig. 1. Schematic diagram of experimental apparatus: 1, nitrogen gas cylinder; 2, regulator; 3, molecular sieve column; 4, mass flow controller; 5 , fast connector; 6 , thermocouple; 7 , holder; 8 , net; 9 , reactor; 10 , heating furnace; 11 , tar collector. 12 , temperature recorder; 13 , temperature controller; 14 , circulating water tank; 15 , hood 
with $\mathrm{CO}_{2}$ in the present study. The procedure was as follows: temperature was increased at $10 \mathrm{~K} / \mathrm{min}$ in an inert flow $\left(\mathrm{N}_{2}, 200 \mathrm{~cm}^{3} / \mathrm{min}\right.$ at STP), switching to $\mathrm{CO}_{2}$ flow $\left(200 \mathrm{~cm}^{3} / \mathrm{min}\right.$ at STP) after reaching the selected temperatures. After activating with $\mathrm{CO}_{2}$ for $1 \mathrm{~h}$, cooling to room temperature was carried out under an inert gas (i.e. $\mathrm{N}_{2}$ ) flow before taking the sample for washing with hot water and drying at $378 \mathrm{~K}$ for further analysis.

The resulting solids after activation were then boiled at about $363 \mathrm{~K}$ with $500 \mathrm{~cm}^{3}$ of $3 \mathrm{~N} \mathrm{HCl}$ for $30 \mathrm{~min}$, filtered in a vacuum flask and washed with warm distilled water several times to remove the chloride ions and other residues. The solids were finally dried at $378 \mathrm{~K}$ for $24 \mathrm{~h}$, and weighed $\left(W_{2}\right)$. The activation yield (Y\%) of the resulting activated carbons was calculated by

$$
Y=\left(W_{1} / W_{2}\right) \times 100
$$

\section{Characterization measurements}

The nitrogen adsorption-desorption isotherms of the samples were obtained at liquid nitrogen temperature (i.e. $77 \mathrm{~K}$ ) using an ASAP 2000 apparatus from Micromeritics (Norcross, GA, U.S.A.). This automatic instrument uses a static volumetric technique. The reference sample from ASAP 2000 manufacturer was used to calibrate the analysis by standard operational procedures before being measured in the experiments, which ensures continued accuracy of results. Prior to the determination of the isotherm, the sample $(\approx 0.2-0.5 \mathrm{~g})$ was outgassed for $2 \mathrm{~h}$ at $523 \mathrm{~K}$ under vacuum to remove the moisture and other contaminants. The specific surface area $\left(S_{\mathrm{BET}}\right)$ of the samples were obtained by means of the standard method of BrunauerEmmett-Teller (BET) applied in a relative pressure range from 0.06 to 0.2 . The total pore volume $\left(V_{\mathrm{t}}\right)$ was assessed by converting the amount of nitrogen gas adsorbed (expressed in $\mathrm{cm}^{3} / \mathrm{g}$ at STP) at a relative pressure $c a .0 .99$ to the volume of liquid adsorbate. The pore size distribution of the whole sample was calculated on the basis of desorption data by employing the Barrett-Joyner-Halenda (BJH) method, and micropore surface area was determined by the t-plot method (Gregg and Sing, 1982). Using the software of the analyzer one can analyze precisely the data calculating the surface areas and pore volume with a variety of methods (e.g. BET method, etc.).

The true density $\left(\rho_{\mathrm{s}}\right)$ of the sample was measured by a helium displacement method with a pycnometer (Lowell and Shields, 1991). The particle density $\left(\rho_{\mathrm{p}}\right)$ was thus calculated from $V_{\mathrm{t}}$ and $\rho_{\mathrm{s}}$.

$$
\rho_{\mathrm{p}}=1 /\left(V_{\mathrm{t}}+1 / \rho_{\mathrm{s}}\right) .
$$

Therefore, the particle porosity $\left(\varepsilon_{\mathrm{p}}\right)$ can be computed from $V_{\mathrm{t}}$ and $\rho_{\mathrm{p}}$ (Smith, 1981).

$$
\varepsilon_{\mathrm{p}}=1-\left(\rho_{\mathrm{p}} / \rho_{\mathrm{s}}\right) \text {. }
$$

Elemental analysis of part of the sample was performed by using an elemental analyzer (Heraeus Co., model CHN-O-RAPID) The inductively coupled plasma-atomic emission spectrometer (JARREL-ASH Co., model ICAP 9000) was used to determine the relevant trace elements.

All characteristic determinations of the resulting activated carbons except surface area and pore volume measurements were replicated at least two times and the means and standard deviations of analytical data were obtained.

\section{RESULTS AND DISCUSSION}

The yield of the resulting activated carbons is in the range of $27 \cdot 0-30 \cdot 4 \%$, listed in Table 1 . The yield was observed to decrease slightly at higher pyrolysis temperature, which is possibly attributed to the volatilization of tar products derived from the lignocellulosic components of raw material (Ahmadpour and Do, 1996). As a result of the shrinkage in the carbon structure at higher pyrolysis temperature, it is reasonable that the true density and particle density of the resulting activated carbons were increased with pyrolysis temperature (Wigmans, 1989), which is consistent with the results shown in Table 1 . The particle porosity is about 0.4 . However, no systematic effect of the pyrolysis temperature on the porosity was observed in the present study.

The BET surface area, the micropore surface area and the percentage of micropore of the resulting activated carbons prepared from corn cob with an impregnation ratio of $100 \mathrm{wt} \%$ with $\mathrm{ZnCl}_{2}$ are given in Table 2. The data in Table 2 show that the effects of the pyrolysis temperature and soaking time play an important role on the surface areas of the resulting activated carbons. Generally, surface areas were observed to decrease at higher pyrolysis temperature and soaking time. However, it should be noted that the pyrolysis temperature of $773 \mathrm{~K}$ and the soaking time of about $0.5 \mathrm{~h}$ were found to be optimal for the higher surface areas presented in this study. The higher surface areas may possibly be due to the opening of the restricted pores. The percentage of micropore related to the effect of pyrolysis temperature was found to generally follow the increase in pyrolysis temperature, but this rate of increase was not as fast as the rate of declination in surface areas.

The surface areas of the resulting activated carbons, which increased rapidly with the impregnation ratio of $\mathrm{ZnCl}_{2}$ are given in Table 3 . The value of the BET surface area is approximately $1400 \mathrm{~m}^{2} / \mathrm{g}$ at $175 \mathrm{wt} \%$ of impregnation ratio. On the other hand, the percentage of micropore compared to the total (BET) surface area decreased as the impregnation ratio of $\mathrm{ZnCl}_{2}$ increased (Hussein et al., 1996). It is also noted that the decrease in the percentage of micropore was rapid at larger impregnation ratios 
Table 1. Densities and porosities of the resulting activated carbons produced at various activation conditions

\begin{tabular}{|c|c|c|c|c|c|}
\hline Activated carbon & $\begin{array}{l}\text { Yield, } Y \\
(\%)\end{array}$ & $\begin{array}{l}\text { Trud density, } \rho_{\mathrm{s}} \\
\qquad\left(\mathrm{g} / \mathrm{cm}^{3}\right)\end{array}$ & $\begin{array}{l}\text { Total pore volume, } V_{\mathrm{t}} \\
\left(\mathrm{g} / \mathrm{cm}^{3}\right)\end{array}$ & $\begin{array}{l}\text { Particle density, } \rho_{\mathrm{p}} \\
\qquad\left(\mathrm{g} / \mathrm{cm}^{3}\right)\end{array}$ & Porosity, $\varepsilon_{\mathrm{p}}$ \\
\hline $100 \%-773 \mathrm{~K}-0.5 \mathrm{~h}^{\mathrm{a}}$ & $28 \cdot 8$ & $1.536 \pm 0.002^{b}$ & $0 \cdot 486$ & 0.876 & 0.430 \\
\hline $100 \%-873 \mathrm{~K}-0.5 \mathrm{~h}$ & $30 \cdot 2$ & $1.639 \pm 0.003$ & $0 \cdot 368$ & $1 \cdot 022$ & $0 \cdot 376$ \\
\hline $100 \%-973 \mathrm{~K}-0.5 \mathrm{~h}$ & $27 \cdot 8$ & $1.750 \pm 0.004$ & $0 \cdot 368$ & $1 \cdot 064$ & $0 \cdot 392$ \\
\hline $100 \%-1073 \mathrm{~K}-0.5 \mathrm{~h}$ & $27 \cdot 8$ & $1 \cdot 850 \pm 0.004$ & $0 \cdot 345$ & $1 \cdot 130$ & $0 \cdot 389$ \\
\hline $100 \%-873 \mathrm{~K}-1 \cdot 0 \mathrm{~h}$ & $30 \cdot 3$ & $1 \cdot 620 \pm 0.002$ & 0.405 & 0.978 & $0 \cdot 396$ \\
\hline $100 \%-973 \mathrm{~K}-1 \cdot 0 \mathrm{~h}$ & $28 \cdot 1$ & $1.749 \pm 0.003$ & $0 \cdot 374$ & $1 \cdot 057$ & $0 \cdot 396$ \\
\hline $100 \%-1073 \mathrm{~K}-1 \cdot 0 \mathrm{~h}$ & $27 \cdot 0$ & $1.868 \pm 0.005$ & $0 \cdot 370$ & $1 \cdot 105$ & $0 \cdot 408$ \\
\hline $100 \%-773 \mathrm{~K}-2 \cdot 0 \mathrm{~h}$ & $30 \cdot 4$ & $1.543 \pm 0.002$ & $0 \cdot 349$ & $1 \cdot 003$ & $0 \cdot 350$ \\
\hline $100 \%-873 \mathrm{~K}-2 \cdot 0 \mathrm{~h}$ & $29 \cdot 4$ & $1.683 \pm 0.002$ & $0 \cdot 393$ & $1 \cdot 013$ & $0 \cdot 398$ \\
\hline $100 \%-973 \mathrm{~K}-2 \cdot 0 \mathrm{~h}$ & $29 \cdot 2$ & $1.764 \pm 0.002$ & $0 \cdot 335$ & $1 \cdot 109$ & 0.371 \\
\hline $100 \%-1073 \mathrm{~K}-2 \cdot 0 \mathrm{~h}$ & $28 \cdot 2$ & $1.901 \pm 0.002$ & $0 \cdot 342$ & $1 \cdot 152$ & $0 \cdot 394$ \\
\hline $100 \%-773 \mathrm{~K}-4 \cdot 0 \mathrm{~h}$ & $29 \cdot 0$ & $1 \cdot 563 \pm 0 \cdot 002$ & $0 \cdot 383$ & 0.978 & $0 \cdot 374$ \\
\hline
\end{tabular}

${ }^{a}$ Denotes the resulting activated carbons prepared in the conditions of the impregnation ratio of $\mathrm{ZnCl}_{2}-$ pyrolysis temperature-soaking time of pyrolysis.

${ }^{b}$ Denotes the mean \pm standard deviation for ten determinations.

of 175 and $200 \mathrm{wt} \%$ under the pyrolysis temperature of $773 \mathrm{~K}$. This indicated that the impregnation ratio of $\mathrm{ZnCl}_{2}$ somehow plays a fairly important role in the formation of micropores, which is parallel to the observation of pore size distribution in Fig. 2. Further comparison of the values of BET surface areas in Table 2 and Table 3 indicated that these values were affected more strongly by the impregnation ratio of $\mathrm{ZnCl}_{2}$ than the pyrolysis temperature.

Table 2. Surface areas of the resulting activated carbons produced with the impregnation ratio of $\mathrm{ZnCl}_{2}$ at 100 wt\%

\begin{tabular}{lccc}
\hline $\begin{array}{l}\text { Activated } \\
\text { carbon }^{\mathrm{a}}\end{array}$ & $\begin{array}{c}\text { BET surface } \\
\text { area } \\
\left(\mathrm{m}^{2} / \mathrm{g}\right)\end{array}$ & $\begin{array}{c}\text { Micropore } \\
\text { surface area } \\
\left(\mathrm{m}^{2} / \mathrm{g}\right)\end{array}$ & $\begin{array}{c}\text { Percentage of } \\
\text { micropore }^{\mathrm{b}}\end{array}$ \\
\hline $673 \mathrm{~K}-0 \cdot 5 \mathrm{~h}$ & 535 & 373 & $69 \cdot 7$ \\
$773 \mathrm{~K}-0 \cdot 5 \mathrm{~h}$ & 960 & 800 & $83 \cdot 3$ \\
$873 \mathrm{~K}-0 \cdot 5 \mathrm{~h}$ & 750 & $\mathrm{NA}^{\mathrm{c}}$ & $\mathrm{NA}^{\mathrm{c}}$ \\
$973 \mathrm{~K}-0 \cdot 5 \mathrm{~h}$ & 747 & 663 & $88 \cdot 8$ \\
$1073 \mathrm{~K}-0 \cdot 5 \mathrm{~h}$ & 706 & 638 & $90 \cdot 4$ \\
& & & \\
$673 \mathrm{~K}-1 \cdot 0 \mathrm{~h}$ & 613 & 462 & $75 \cdot 4$ \\
$773 \mathrm{~K}-1 \cdot 0 \mathrm{~h}$ & 911 & 762 & $83 \cdot 6$ \\
$873 \mathrm{~K}-1 \cdot 0 \mathrm{~h}$ & 820 & 717 & $87 \cdot 4$ \\
$973 \mathrm{~K}-1 \cdot 0 \mathrm{~h}$ & 786 & $\mathrm{NA}$ & $\mathrm{NA}$ \\
$1073 \mathrm{~K}-1 \cdot 0 \mathrm{~h}$ & 757 & 676 & $89 \cdot 3$ \\
& & & \\
$773 \mathrm{~K}-2 \cdot 0 \mathrm{~h}$ & 774 & 673 & $87 \cdot 0$ \\
$873 \mathrm{~K}-2 \cdot 0 \mathrm{~h}$ & 791 & 694 & $87 \cdot 7$ \\
$973 \mathrm{~K}-2 \cdot 0 \mathrm{~h}$ & 682 & 610 & $89 \cdot 4$ \\
$1073 \mathrm{~K}-2 \cdot 0 \mathrm{~h}$ & 721 & 651 & $90 \cdot 3$ \\
& & & \\
$773 \mathrm{~K}-4 \cdot 0 \mathrm{~h}$ & 783 & 677 & $86 \cdot 5$ \\
$873 \mathrm{~K}-4 \cdot 0 \mathrm{~h}$ & 744 & 660 & $88 \cdot 7$ \\
$973 \mathrm{~K}-4 \cdot 0 \mathrm{~h}$ & 703 & 629 & $89 \cdot 5$ \\
$1073 \mathrm{~K}-4 \cdot 0 \mathrm{~h}$ & 688 & 624 & $90 \cdot 7$ \\
\hline
\end{tabular}

${ }^{\text {a }}$ Denotes the resulting activated carbons prepared in the conditions of pyrolysis temperature and soaking time.

bercentage of micropore is defined as the ratio of micropore surface area to BET surface area.

"Not available.
Physical activation of corn cob was carried out at two temperatures of 1073 and $1173 \mathrm{~K}$ in a $\mathrm{CO}_{2}$ atmosphere. The BET surface area increases from 437 to $777 \mathrm{~m}^{2} / \mathrm{g}$ in the experimental range studied. The trend suggests that the microporosity is more developed at $1073 \mathrm{~K}$ compared to that at $1173 \mathrm{~K}$. Comparing the results in Table 3 with those of the physically activated samples show that the chemical activation with commonly used chemicals, $\mathrm{ZnCl}_{2}$, produced activated carbons having well-developed porosities. Further studies on the physical activation with $\mathrm{CO}_{2}$ and/or steam from corn cobs need to be made.

A typical example in this study is shown in Fig. 3. The activated carbon prepared from corn cob impregnated with $\mathrm{ZnCl}_{2}$ indicated a typical Type I isotherm according to the Brunauer-DemingDeming-Teller (BDDT) classification (Gregg and Sing, 1982). The Type I isotherms exhibit no hysteresis at all, and they are characteristic of microporous solids having a small external surface area, the

Table 3. Surface areas of the resulting activated carbons produced at a pyrolysis temperature of $773 \mathrm{~K}$

\begin{tabular}{lccc}
\hline $\begin{array}{l}\text { Activated } \\
\text { carbon }^{\mathrm{a}}\end{array}$ & $\begin{array}{c}\text { BET surface } \\
\text { area } \\
\left(\mathrm{m}^{2} / \mathrm{g}\right)\end{array}$ & $\begin{array}{c}\text { Micropore } \\
\text { surface area } \\
\left(\mathrm{m}^{2} / \mathrm{g}\right)\end{array}$ & $\begin{array}{c}\text { Percentage of } \\
\text { micropore }\end{array}$ \\
\hline $75 \%-0 \cdot 5 \mathrm{~h}^{\mathrm{a}}$ & 651 & 543 & $83 \cdot 4$ \\
$100 \%-0.5 \mathrm{~h}$ & 960 & 800 & $83 \cdot 3$ \\
$150 \%-0.5 \mathrm{~h}$ & 1114 & 889 & $79 \cdot 8$ \\
$175 \%-0.5 \mathrm{~h}$ & 1410 & 899 & $63 \cdot 8$ \\
$75 \%-1.0 \mathrm{~h}$ & 725 & 622 & $85 \cdot 8$ \\
$100 \%-1.0 \mathrm{~h}$ & 911 & 762 & $83 \cdot 6$ \\
$150 \%-1.0 \mathrm{~h}$ & 1139 & 928 & $81 \cdot 5$ \\
$175 \%-1.0 \mathrm{~h}$ & 1338 & 912 & $68 \cdot 2$ \\
$200 \%-1.0 \mathrm{~h}$ & 1563 & 874 & $55 \cdot 9$ \\
\hline
\end{tabular}

${ }^{a}$ Denotes the resulting activated carbons prepared in the condition of the impregnation ratio of $\mathrm{ZnCl}_{2}$ and soaking time of pyrolysis. 
limiting uptake being governed by the accessible micropore volume rather than by the internal surface area. This is also a characteristic of materials with narrow pore size distribution that are essentially microporous as illustrated in Fig. 2.

In order to obtain the preliminary information on adsorption capacity of the resulting activated carbon, the experiments were conducted at $1009 \mathrm{ppmv}$ inlet concentration of 1,1-dichloro-1-fluro-ethane (HCFC-

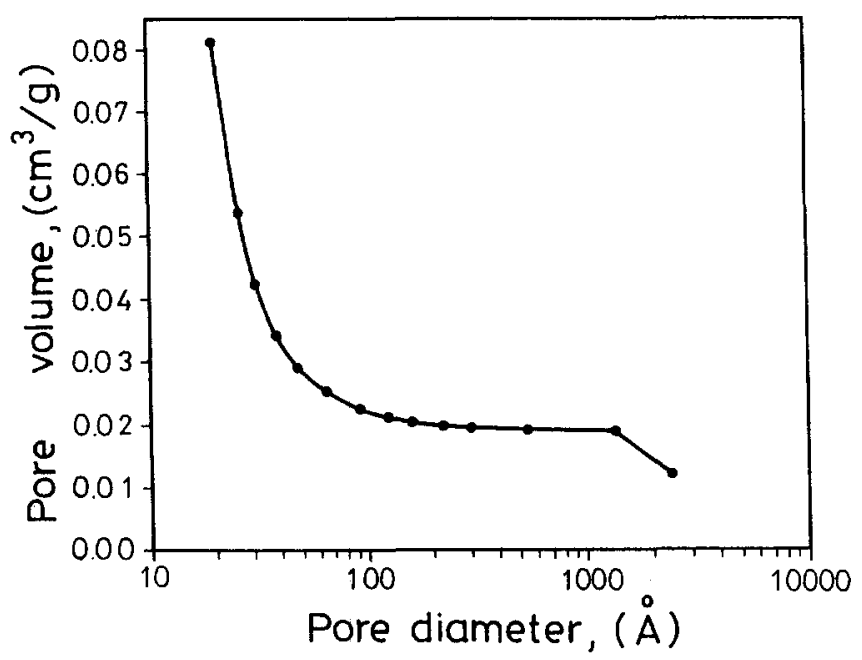

Fig. 2. Pore size distribution of the resulting activated carbon obtained from corn cob precursor. Activation conditions: impregnation ratio of $100 \mathrm{wt} \%$, pyrolysis temperature of $773 \mathrm{~K}$, soaking time of $0.5 \mathrm{~h}$ 141b) and an adsorption temperature of $298 \mathrm{~K}$. The amount of HCFC-141b adsorbed per gram of the resulting activated carbon (with BET surface area and micropore surface area of 1410 and $899 \mathrm{~m}^{2} / \mathrm{g}$, respectively, as described in Table 3) was $0 \cdot 275 \mathrm{~g} / \mathrm{g}$. For comparative purposes, with the same adsorbate at the same inlet concentration of HCFC-141b and

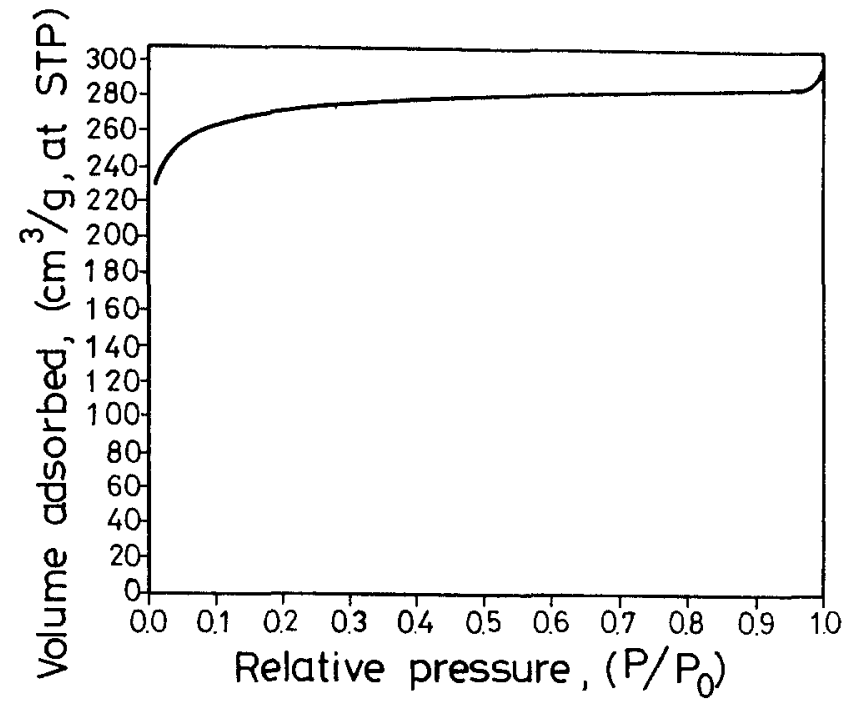

Fig. 3. Adsorption isotherm (at $77 \mathrm{~K}$ ) of nitrogen of the resulting activated carbon obtained from corn cob precursor. Activation conditions: impregnation ratio of $100 \mathrm{wt} \%$, pyrolysis temperature of $773 \mathrm{~K}$, soaking time of $0.5 \mathrm{~h}$

Table 4. Elemental analyses of corn cob and some activated carbons produced at various activation conditions

\begin{tabular}{lcccc}
\hline Sample & \multicolumn{4}{c}{ Elemental analysis (wt\%) } \\
\cline { 2 - 5 } & $\mathrm{C}$ & $\mathrm{H}$ & $\mathrm{N}$ & $\mathrm{S}$ \\
\hline Corn cob & $46 \cdot 84 \pm 0 \cdot 06^{\mathrm{b}}$ & $5 \cdot 96 \pm 0 \cdot 02$ & $0 \cdot 88 \pm 0 \cdot 02$ & $\mathrm{ND}^{\mathrm{c}}$ \\
$20 \%-1073 \mathrm{~K}-4 \cdot 0 \mathrm{~h}^{\mathrm{a}}$ & $88 \cdot 41 \pm 0 \cdot 85$ & $1 \cdot 05 \pm 0 \cdot 08$ & ND & NA $^{\mathrm{d}}$ \\
$50 \%-1073 \mathrm{~K}-4 \cdot 0 \mathrm{~h}$ & $86 \cdot 16 \pm 0 \cdot 26$ & $1 \cdot 22 \pm 0 \cdot 20$ & ND & NA \\
$100 \%-1073 \mathrm{~K}-4 \cdot 0 \mathrm{~h}$ & $90 \cdot 31 \pm 0 \cdot 64$ & $0 \cdot 84 \pm 0 \cdot 05$ & & ND \\
\hline
\end{tabular}

${ }^{\text {a Notation is stated in Table } 1 .}$.

${ }^{b}$ Denote the mean \pm standard deviation for at least two determinations.

${ }^{c}$ Not detectable, values less than $0.01 \mathrm{wt} \%$.

dNot available.

Table 5. Contents of relevant trace elements of some activated carbons at various activation conditions

\begin{tabular}{lccccccc}
\hline Activated carbon & \multicolumn{7}{c}{ Trace element (ppm) } \\
\cline { 2 - 8 } & \multicolumn{1}{c}{$\mathrm{Zn}$} & $\mathrm{Si}$ & $\mathrm{Cr}$ & $\mathrm{Ni}$ & $\mathrm{Cu}$ & $\mathrm{Fe}$ & $\mathrm{Al}$ \\
\hline $20 \%-1073 \mathrm{~K}-4 \cdot 0 \mathrm{~h}^{\mathrm{a}}$ & $6780 \pm 48^{\mathrm{b}}$ & $1570 \pm 21$ & $722 \pm 3$ & $34 \pm 1 \cdot 1$ & $\mathrm{ND}^{\mathrm{c}}$ & $405 \pm 18$ & $\mathrm{ND}$ \\
$50 \%-1073 \mathrm{~K}-2 \cdot 0 \mathrm{~h}$ & $3888 \pm 38$ & $429 \pm 2$ & $41 \pm 1 \cdot 4$ & $7 \cdot 4 \pm 0 \cdot 7$ & $1 \cdot 1 \pm 0 \cdot 1$ & $\mathrm{ND}$ & $\mathrm{ND}$ \\
$100 \%-773 \mathrm{~K}-0 \cdot 5 \mathrm{~h}$ & $1745 \pm 19$ & $285 \pm 7$ & $18 \pm 0 \cdot 7$ & $6 \cdot 3 \pm 0 \cdot 4$ & $14 \pm 0 \cdot 8$ & $\mathrm{ND}$ & $\mathrm{ND}$ \\
$100 \%-1073 \mathrm{~K}-4 \cdot 0 \mathrm{~h}$ & $1107 \pm 6$ & $1583 \pm 11$ & $207 \pm 10$ & $20 \pm 0 \cdot 4$ & $14 \pm 0 \cdot 8$ & $753 \pm 31$ & $380 \pm 13$ \\
\hline
\end{tabular}

${ }^{\text {a }}$ Notation as stated in Table 1.

${ }^{b}$ Denotes the mean \pm standard deviation for three determinations.

'Not detectable. 
adsorption temperature, the adsorption capacities of two commercial activated carbons PCB and BPL (Calgon Carbon Co., Pittsburgh, U.S.A.) were 0.274 and $0.198 \mathrm{~g} / \mathrm{g}$, respectively, which was lower than that of the resulting activated carbon. This is consistent with the measured micropore volumes of 853 and $621 \mathrm{~m}^{2} / \mathrm{g}$ for carbons PCB and BPL, respectively, described previously (Tsai and Chang, 1994a).

The results of the ultimate analysis of corn cob and three activated carbons prepared from corn cob in this study are given in Table 4 . The $\mathrm{H} / \mathrm{C}$ atomic ratio of corn cob is $\approx 1.51$ which is a characteristic of its cellulose $(\mathrm{H} / \mathrm{C}=1.67)$ and hemicellulose textures (Bagby and Widstrom, 1987; Heschel and Klose, 1995). The resulting activated carbons contain nearly $90 \mathrm{wt} \%$ of carbon, which is obviously higher than that (i.e. $46.84 \pm 0.06 \mathrm{wt} \%$ ) of raw precursor and approximate to the commercial product specifications (Tsai and Chang, 1994b). On the other hand, the non-carbon elements (hydrogen, oxygen, traces of nitrogen and sulfur) were mostly removed in a gaseous form during the chemical activation, resulting in low analysis values for these elements (Wigmans, 1989).

The contents of relevant trace elements in the composition data of some of the resulting activated carbons are listed in Table 5. The content of $\mathrm{Zn}$ and $\mathrm{Si}$ appear to be the two largest trace element sources. These trace elements such as Si exist mainly in the forms of minerals or ashes, resulting in the impact on the increase of the hydrophilicity of activated carbon slightly similar to that of silica gel for the adsorption of polar compounds (Ruthven, 1984; Suzuki, 1990). In Table 5, the contents of transition metal elements such as $\mathrm{Cu}$ and $\mathrm{Fe}$ of the resulting activated carbons are very low as compared to those of the commercial activated carbon specifications (Tsai and Chang, 1994b). This information is very important during steam regeneration of activated carbon. There have been reports inferring that the hydrolysis reaction between activated carbon and some adsorbates of halogenated hydrocarbons is possibly attributed to the presence of these transition metals on the active sites of carbon surface (Kenson, 1985).

In conclusion, the chemical activation process was used to prepare activated carbons from agricultural waste corn cob with $\mathrm{ZnCl}_{2}$ in the present study. Under the experimental conditions investigated, the resulting activated carbons are essentially microporous materials. From the results in Table 2 and Table 3, the temperature of $773 \mathrm{~K}$, the impregnation ratio of $175 \mathrm{wt} \%$ and the soaking time of $0.5 \mathrm{~h}$ were found to be the optimal conditions for producing high surface area carbons (i.e. $1410 \mathrm{~m}^{2} / \mathrm{g}$ ). The resulting activated carbons may be used to effectively treat drinking water, wastewater, industrial gas, and indoor air environments due to their high adsorption capacities.

\section{ACKNOWLEDGEMENTS}

This research was supported by a grant from the National Science Council, Taiwan, under contract number NSC 85-2211-E-041-002.

\section{REFERENCES}

Ahmadpour, A. \& Do, D. D. (1996). The preparation of active carbons from coal by chemical and physical activation. Carbon, 34, 471-479.

Bagby, M. O. \& Widstrom, E. W. (1987). Biomass uses and conversions. In Corn: Chemistry and Technology, ed. S. A. Waston \& P. E. Ramstad, pp. 575-590. American Association of Cereal Chemists, MN.

Bansal, R. C., Donnet, J. B. \& Stoeckli, F. (1988). Active Carbon, pp. 4-22. Marcel Dekker, New York.

Domingo-Garcia, M., Fernandez-Morales, I., LopezGarzon, F. J. \& Moreno-Castilla, C. (1991). Use of activated carbons obtained from agricultural byproducts for the adsorption of some hydrocarbons. Langmuir, 7, 339-343.

Gergova, K., Petrov, N. \& Eser, S. (1994). Adsorption properties and microstructure of activated carbons produced from agricultural by-products by steam pyrolysis. Carbon, 32, 693-702.

Girgis, B. S., Khalil, L. B. \& Tawfik, T. A. M. (1994). Activated carbon from sugar cane bagasse by carbonization in the presence of inorganic acids. J. Chem. Tch. Biotechnol., 61, 87-92.

Gregg, S. J. \& Sing, K. S. W. (1982). Adsorption, Surface Area and Porosity, 2nd ed., pp. 195-228. Academic Press, New York.

Guzel, F. \& Tez, Z. (1993). The characterization of the micropore structures of some activated carbons of plant origin by $\mathrm{N}_{2}$ and $\mathrm{CO}_{2}$ adsorptions. Separation Sci. Tech., 28, $1609-1627$.

Heschel, W. \& Klose, E. (1995). On the suitability of agricultural by-products of the manufacture of granular activated carbon. Fuel, 74, 1786-1791.

Hussein, M. Z., Tarmizi, R. S. H., Zainal, Z., Ibrahim, R. \& Badri, M. (1996). Preparation and characterization of active carbons from oil palm shells. Carbon, 34, 1447-1449.

Kenson, R. E. (1985). Recovery and reuse of solvents from VOC air emissions. Environ. Progress, 4, 161-164.

Khalil, L. B. (1996). Adsorption characteristics of activated carbon obtained from rice husks by treatment with phosphoric acid Adsorption Sci. Tech., 13, 317-325.

Lessier, M. C., Shull, J. C. \& Miller, D. J. (1994). Activated carbon from cherry stones Carbon, 30, 1493-1498.

Lowell, S. \& Shields, J. E. (1991). Powder Surface Area and Porosity, 3rd ed., pp. 227-230. Chapman \& Hall, London.

Maschio, G., Koufopanos, C. \& Lucchesi, A. (1992). Pyrolysis, a promising route for biomass utilization. Bioresource Technology, 42, 219-231.

Nguyen, C., Ahmadpour, A. \& Do, D. D. (1995). Effects of gasifying agents on the characterization of nut shellderived activated carbon. Adsorption Sci. Tech., 12, 247-258.

Noll, K. E., Gounaris, V. \& Hon, W. S. (1992). Adsorption Technology for Air and Water Pollution Control, pp. 3-6. Lewis, Chelsea, U.S.A.

Periasamy, K. \& Namasivayam, C. (1995). Adsorption of $\mathrm{Pb}$ (II) by peanut hull carbon from aqueous solution. Separation Sci. Tech., 30, 2223-2237. 
Philip, C. A. \& Girgis, B. S. (1996). Adsorption characteristics of microporous carbons from apricot stones activated by phosphoric acid. J. Chem. Tech. Biotechnol., 67, 248-254.

Pollard, S. J. T., Fowler, G. D., Sollars, C. J. \& Perry, R. (1992). Low-cost adsorbents for waste and wastewater treatment: a review. Sci. Total Environ., 116, 31-52.

Rodriguez-Reinoso, F. \& Molina-Sabio, M. (1992). Activated carbons from lignocellulosic materials by chemical and/or physical activation: an overview. Carbon, 30, 1111-1118.

Ruthven, D. M. (1984). Principles of Adsorption and Adsorption Process, pp. 9-12. Wiley, New York.

Smith, J. M. (1981). Chemical Engineering Kinetics, 3rd ed., pp. 334-338. McGraw-Hill, New York.

Suzuki, M. (1990). Adsorption Engineering, pp. 9-11. Elsevier, New York.
Torregrosa, R. \& Martin-Martinez, J. M. (1991). Activation of lignocellulosic: a comparison between chemical, physical and combined activation in terms of porous texture. Fuel, 70, 1173-1180.

Tsai, W. T. \& Chang, C. Y. (1994). Adsorption of methylene chloride vapor on activated carbons. J. Chem. Tech. Biotechnol., 61, 145-151.

Tsai, W. T. \& Chang, C. Y. (1994). Surface chemistry of activated carbons and its relevance for effects of relative humidity on adsorption of chlorinated organic vapors. Chemosphere, 29, 2507-2515.

Wigmans, T. (1989). Industrial aspects of production and use of activated carbons. Carbon, 27, 13-22.

Yang, S. S., Wei, C. B., Ku, K. \& Tsai, S. S. (1991). Food and agricultural wastes produced in Taiwan area (in Chinese). J. Chinese Institute of Biomass Energy (Taiwan), 10, 70-87. 